\title{
Fitomorfologia e produção de cultivares de trigo duplo propósito em diferentes manejos de corte e densidades de semeadura
}

\author{
Phytomorphology and production of dual purpose wheat with different cutting regimes and \\ seeding density \\ Thomas Newton Martin ${ }^{I *}$ Cláudio César Simionatto ${ }^{\mathrm{I}}$ Patrícia Bertoncelli ${ }^{\mathrm{I}}$ Sidney Ortiz ${ }^{\mathrm{I}}$ \\ Marcel Hastenpflug ${ }^{\mathrm{II}}$ Magnos Fernando Ziech ${ }^{\mathrm{I}}$ André Brugnara Soares ${ }^{\mathrm{III}}$
}

\section{RESUMO}

A diversificação de cultivares e finalidades da cultura do trigo podem alterar as indicações de manejo no sistema de integração lavoura-pecuária. Dessa forma, este trabalho tem como objetivo verificar o desempenho das cultivares de trigo duplo propósito em diferentes densidades de semeadura, com e sem corte. As cultivares de trigo utilizados foram: 'BRS Figueira', 'BRS Guatambu', 'BRS Tarumã' $e$ 'BRS Umbu', e as densidades de semeadura utilizadas foram de 50, 200, 350, 500 e 650 sementes por metro quadrado. As variáveis fitomorfológicas e de produção possuem um desempenho diferenciado conforme a cultivar, o manejo e a densidade de semeadura. A cultivar 'Figueira' possui o maior potencial produtivo dentro dos limites de densidades estudados quanto à produção de massa seca, em relação aos demais cultivares. A produção de grãos teve interação significativa entre as cultivares e o manejo (com e sem corte). As cultivares com maiores produções de grãos foram, respectivamente, 'Figueira', 'Umbu', 'Tarumã' $e$ 'Guatambu' no manejo sem corte, já no sistema com corte a cultivar 'Tarumã' foi a que obteve o maior rendimento de grãos, diferenciando-se das demais. A maioria das correlações altas e significativas ocorreu nos manejos com e sem corte. O corte diminuiu todos os valores dos componentes de rendimento, bem como a produção de grãos de todos as cultivares.

Palavras-chave: densidade de semeadura, integração lavoura-pecuária, manejo de produção.

\section{ABSTRACT}

The diversification of cultivars and purposes of wheat crop may alter the information management system of crop-livestock integration. Therefore, this research has the objective to verify the performance of dual purpose wheat with different cutting regimes and seeding density. The whet cultivate used were: 'BRS Figueira', 'BRS Guatambu', 'BRS Tarumã' and 'BRS Umbu'. The seeding density was of 50, 200, 350, 500 and 650 seeds for square meter. The phitomorfological and production variables have a different performance depending on as cultivar, management and seeding density. The cultivar 'Figueira' has the highest productive potential yield within the range of densities analyzed for dry mater production in relation to other cultivars The grain yield had significant interaction between cultivars and management (with and without cutting). The cultivars with higher grain yields were, respectively, 'Figueira', 'Umbu', 'Tarumã' and 'Guatambu' in managing blunt, already in the court system the cultivar 'Tarumã' was the one that had the highest grain yield, differing from the others. The most high and significant correlations occurred in plots with and without cutting. The court dropped all values of yield components, and grain yield of all cultivars.

Key words: seeding density, crop-livestock integration, regimes production.

\section{INTRODUÇÃO}

Na região Sul do Brasil, são observados desequilíbrios nutricionais nos rebanhos, em razão da irregularidade de produção de forragem, na estação fria, provocada pela diminuição da quantidade e qualidade da forragem fornecida, acarretando uma significativa diminuição na produção de leite e carne

IUniversidade Tecnológica Federal do Paraná (UTFPR), Campus Dois Vizinhos. Estrada para Boa Esperança, km 04, 85660-000,

Dois Vizinhos, PR, Brasil. E-mail: martin@utfpr.edu.br. Autor para correspondência.

IUniversidade Federal de Santa Maria (UFSM), Santa Maria, RS, Brasil.

IIUTFPR, Campus Pato Branco, Pato Branco, PR, Brasil. 
(WENDT et al., 2006). A resolução do problema passa por alternativas de alimentação na estação fria, dentre estas, podem ser citadas a melhoria do manejo nas áreas, a utilização do sistema de integração lavourapecuária e o fornecimento de silagem e/ou feno. Ao serem utilizados cereais de inverno na alimentação animal, em locais e períodos problemáticos (vazio forrageiro), pode haver melhorias no aproveitamento do potencial da propriedade (BORTOLINI et al., 2004), agregando renda à propriedade. O sistema de integração lavoura-pecuária mais comum no Sul do Brasil consiste em concentrar a produção de grãos no período quente do ano, principalmente usando os cultivos de soja e milho, e a produção animal no inverno, usando principalmente aveias e azevém. BALBINOT JUNIOR et al. (2009) discutem os fundamentos e as características do sistema de integração lavoura-pecuária para a região Sul do Brasil. Outra alternativa de forrageamento aos animais é o uso de cereais de dupla aptidão, que servem para prover forragem aos animais até um determinado momento e, posteriormente, a cultura é diferida para produção de grãos. Nesse sentido, uma gramínea de dupla aptidão que pode ser utilizada no inverno é o trigo, cultivado em todo o mundo, objetivando principalmente a produção de grãos, mas podendo ser utilizado também como forragem para os animais dentro do mesmo cultivo. Algumas informações a respeito de técnicas de manejo devem ser seguidas para a obtenção de sucesso na utilização do trigo duplo propósito, como, por exemplo, o momento correto da retirada dos animais da área, o que evita danos ao meristema apical, possibilitando a elongação dos entre nós e viabilizando a produção de grãos. As épocas de entrada e saída dos animais dependem da região, pois estas são determinadas por aspectos fenológicos da cultura e estes, por sua vez, são influenciados por variáveis climáticas (temperatura, fotoperíodo e disponibilidade hídrica) e de manejo (disponibilidade de nutrientes e parâmetros edáficos). Outra questão que deve ser considerada são os preços dos produtos (produto animal e grão de trigo) e os custos de produção.

No Paraná, são limitados os estudos sobre o manejo do trigo de duplo propósito, apesar do potencial dessa cultura. O trigo, além de ser uma das principais culturas da região, pode suprir a falta de forragem causada pela redução de produção das pastagens perenes de verão durante o inverno, devido não somente à produção de forragem, mas também ao seu valor nutritivo, comparado à alfafa, em relação à digestibilidade e aos teores de proteína bruta (HASTENPFLUG, 2009).
Entre as características importantes para que uma cultivar tenha dupla aptidão está a produção de forragem e de grãos, a tolerância ao pastejo ou corte (DEL DUCA et al., 1999), a alta capacidade de perfilhamento, o rápido estabelecimento e o crescimento ereto ou semiereto, o que é favorável para a produção de forragem, o longo período vegetativo e a fase reprodutiva curta (WENDT et al., 2006). Entre as características importantes para a produção de grãos e forragem destaca-se a capacidade de perfilhamento (DAVIDSON \& CHEVALIER, 1990), que é influenciada por aspectos genéticos (SPARKES et al., 2006), água, nutrição mineral (nitrogênio principalmente), florescimento, luz, fotoperíodo, temperatura e cortes (LANGER, 1963). Além dos aspectos citados anteriormente, a densidade de semeadura também influencia diretamente a produção de afilhos e consequentemente a produção de forragem e grãos (ZAFFARONI et al., 1998). Muitas vezes, em se tratando de propriedade, a densidade de semeadura é aumentada para antecipar a entrada dos animais na pastagem, diminuindo assim o vazio forrageiro de outono. Segundo HÖFS (2004), para que um número ideal de plantas seja alcançado em uma lavoura, um dos fatores mais importantes a ser considerado é a densidade de semeadura. RIEFFEL NETO et al. (2000) recomendam que, quando o controle de plantas daninhas e o manejo da irrigação são realizados adequadamente na cultura do arroz, a densidade de semeadura pode ser reduzida, além disso deve-se observar a qualidade das sementes.

A recomendação de semeadura de trigo duplo propósito para a região Sul do Brasil é de uma densidade de 350 a 400 sementes viáveis por metro quadrado. Para a produção exclusiva de cereais de inverno, o espaçamento utilizado entre linhas é de $17 \mathrm{~cm}$, e o recomendado é que não sejam ultrapassados $20 \mathrm{~cm}$, o que resultaria na utilização de 90 a $110 \mathrm{~kg}$ de semente por hectare (DEL DUCA et al., 1999).

Este trabalho teve como objetivo avaliar o desempenho de quatro cultivares de trigo duplo propósito em diferentes densidades de semeadura, com e sem corte.

\section{MATERIAL E MÉTODOS}

O experimento foi realizado na área experimental da Universidade Tecnológica Federal do Paraná, no Campus Dois Vizinhos, no período entre maio e novembro de 2008. A região está situada no Terceiro Planalto Paranaense, com altitude de $520 \mathrm{~m}$, latitude de $25^{\circ} 44^{\prime \prime}$ Sul e longitude de $53^{\circ} 04^{\prime}$ ' Oeste. O clima é classificado como subtropical úmido mesotérmico (Cfa), segundo a classificação de Köppen 
(MAACK, 1968). O solo pertence à Unidade de mapeamento NITOSSOLO VERMELHO distroférrico úmbrico, com textura argilosa de fase floresta subtropical perenifólia e relevo ondulado (BHERING et al., 2008). O sistema de cultivo utilizado foi de cultivo mínimo. As práticas culturais seguiram as indicações da COMISSÃO SUL BRASILEIRA DE PESQUISA DE TRIGO (EMBRAPA-CNPT, 2006). A semeadura foi realizada no dia 17 de maio de 2008, com uma adubação de base de $60 \mathrm{~kg} \mathrm{ha}^{-1}$ (N-P-K de formulação 10-15-15), conforme laudo de análise do solo. No início do perfilhamento, foi realizada uma adubação nitrogenada a lanço, com $60 \mathrm{~kg}$ de $\mathrm{N}$ por ha, sendo utilizado como fonte de nitrogênio o sulfato de amônio ( $20 \%$ de N).

O delineamento experimental foi o de blocos completamente casualizados, em que os tratamentos foram distribuídos em um arranjo fatorial (cultivares $\mathrm{x}$ densidades de semeaduras), nas parcelas principais, com parcelas subdivididas (manejos de corte). As cultivares de trigo utilizadas foram: 'BRS Figueira', 'BRS Guatambu', 'BRS Tarumã' e 'BRS Umbu', cedidas pela EMBRAPA. As densidades de semeadura utilizadas foram de 50, 200, 350, 500 e 650 sementes por metro quadrado. As subparcelas foram divididas conforme o manejo de corte (sem corte e um corte). O corte foi realizado quando o trigo atingiu uma altura de $30 \mathrm{~cm}$, sendo deixado um resíduo de $10 \mathrm{~cm}$ do solo. A parcela experimental foi constituída de cinco fileiras espaçadas $17 \mathrm{~cm}$ uma das outras, totalizando um metro de largura por 3,5m de comprimento; a área útil das subparcelas foram compostas por três fileiras de $50 \mathrm{~cm}$ de comprimento, totalizando uma área de $0,255 \mathrm{~m}^{2}$.

As avaliações foram realizadas no centro de cada subparcela, na fileira central, $0,5 \times 0,51 \mathrm{~m}$, em que foram avaliados: número de espigas (parcela útil), massa de espigas (total da parcela), produção de grãos (ajustada para 13\% de umidade), massa dos grãos em cinco espigas (cinco espigas), número de grãos em cinco espigas, massa de cem grãos, número de espiguetas, massa de espigas, estatura de plantas (média de três plantas mensuradas da base do solo até a inserção do último nó que liga o colmo e a espiga), mensurado no período do florescimento pleno, fitomassa seca da parte aérea (estimada a partir de uma amostra coletada no momento do corte e secada em estufa de circulação forçada a $65^{\circ} \mathrm{C}$ até massa constante) e perfilhamento (estimado em pleno desenvolvimento vegetativo, em que as plantas foram contadas na fileira central ao longo de cinquenta centímetros). Os dados obtidos foram submetidos à análise de variância (teste F), e as médias dos tratamentos, quando qualitativas, foram comparadas por meio do teste de Duncan, a 5\% de probabilidade de erro, e quando quantitativas foram submetidas à análise de regressão (até terceiro grau). Os dados foram analisados por meio do software Soc-NTIA (EMBRAPA, 1997).

\section{RESULTADOS E DISCUSSÕES}

Os resultados da análise de variância foram desdobrados conforme as interações pertinentes e são apresentados nas tabelas 1 e 2 e na figura 1 . A partir da tabela 1 , verifica-se que as variáveis número de espigas por parcela e número de grãos em cinco espigas não apresentaram interação entre os fatores estudados. Dessa forma, verifica-se que o maior número de espigas formadas ocorreu na cultivar 'Tarumã', porém isso não refletiu em maior número de grãos, pelo contrário, houve diminuição no número de grãos por espiga. Em relação ao número de grãos em cinco espigas (NG5E), a cultivar que apresentou maior média foi a 'Figueira', não se diferenciando da 'Umbu’. Quanto aos manejos de corte, verificou-se em ambas as variáveis que o manejo sem corte foi superior ao manejo com corte. A capacidade de perfilhamento ocorre por diversos fatores, inclusive pela coordenação e pelo sincronismo entre o desenvolvimento de folhas e o perfilhamento, conhecido como ocupação de sítios (VALÉRIO et al., 2009). Esses resultados concordam com os resultados de número de espiguetas, massa das espigas, massa de cem grãos, produção de grãos e estatura de plantas (interação significativa para cultivar x manejo) (Tabela 2), em que foi verificado que os manejos sem corte foram sempre superiores e diferentes em relação ao manejo com corte.

Quanto às características genotípicas (Tabela 2), verifica-se que o número de espiguetas foi superior na cultivar 'Guatambu' (com e sem corte), já a

Tabela 1 - Médias das cultivares e dos manejos sem corte e um corte para o desdobramento da análise de variância para as variáveis número de espigas por parcela (NE) e número de grãos em cinco espigas (NG5E). UTFPR, Campus Dois Vizinhos, 2009.

\begin{tabular}{lll}
\hline Cultivares & \multicolumn{1}{c}{ NE } & NG5E \\
\hline 'Figueira' & $72,69 \mathrm{~b} *(285,06)^{\#}$ & $98,53 \mathrm{a} *$ \\
'Guatambu' & $73,20 \mathrm{~b}(287,06)$ & $80,33 \mathrm{~b}$ \\
'Tarumã' & $132,24 \mathrm{a}(518,59)$ & $63,96 \mathrm{c}$ \\
'Umbu' & $54,98 \mathrm{c}(215,61)$ & $93,11 \mathrm{a}$ \\
& & \\
Sem corte & $128,42 \mathrm{a}(503,61)$ & $106,97 \mathrm{a}$ \\
Com corte & $60,71 \mathrm{~b}(238,08)$ & $72,49 \mathrm{~b}$ \\
\hline
\end{tabular}

*As médias não ligadas pela mesma letra diferem pelo teste de comparação de médias de Duncan, a 5\% de probabilidade de erro. \# valores para número de espigas por $\mathrm{m}^{2}$ obtido nas parcelas. 


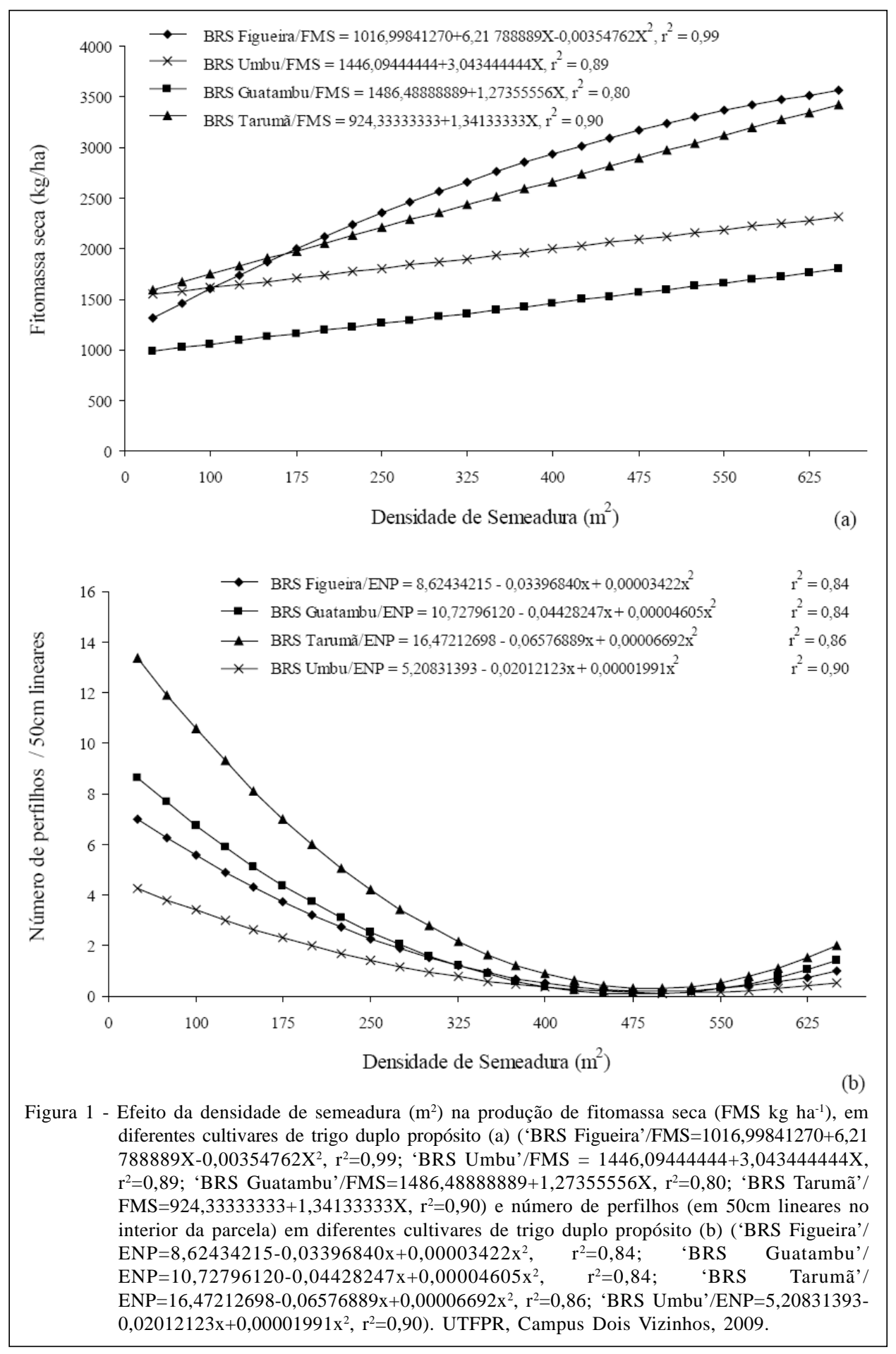

massa de espigas sem corte foi superior na cultivar 'Figueira' e com corte para a 'Tarumã' e a variável massa de cem grãos foi superior na cultivar 'Umbu' (sem corte), e 'Umbu' e 'Tarumã' (com corte). A produtividade de grãos foi superior na cultivar 'Figueira' no manejo sem corte e no manejo com corte foi superior na cultivar
'Tarumã'. Quanto à estatura de planta, verifica-se que as cultivares 'Guatambu' e 'Umbu' tiveram as maiores estaturas (sem corte) e no manejo com corte somente a 'Guatambu' se destacou (Tabela 2). A estatura de planta é uma das variáveis de maior influência na diversidade genética de trigo. Segundo WENDT et al. (20060, as

Ciência Rural, v.40, n.8, ago, 2010. 
Tabela 2 - Médias das cultivares nos manejos sem corte (SC) e com corte (CC) para o desdobramento da análise de variância para as variáveis número de espiguetas (NEsp), massa de espigas (ME, g), massa de cem grãos (MCG, g), produção de grãos (PG, kg ha ${ }^{-1}$ ) e estatura de planta (EP, cm). UTFPR, Campus Dois Vizinhos, 2009.

\begin{tabular}{|c|c|c|c|c|c|}
\hline & NEsp & $\mathrm{ME}$ & MCG & PG & EP \\
\hline 'Figueira' & $60,47 \mathrm{bA} *$ & $86,76 \mathrm{aA}$ & $2,40 \mathrm{bA}$ & $2437,87 \mathrm{aA}$ & $59,07 \mathrm{bA}$ \\
\hline 'Guatambu' & $69,87 \mathrm{aA}$ & $44,96 \mathrm{cA}$ & $1,75 \mathrm{cA}$ & $871,81 \mathrm{dA}$ & $67,23 \mathrm{aA}$ \\
\hline ‘Tarumã’ & 53,60cA & $54,85 \mathrm{bA}$ & $1,63 \mathrm{cA}$ & $1210,90 \mathrm{cA}$ & $56,33 \mathrm{bA}$ \\
\hline 'Umbu’' & 52,93cA & $53,18 \mathrm{bA}$ & $2,76 \mathrm{aA}$ & $1593,10 \mathrm{bA}$ & $67,95 \mathrm{aA}$ \\
\hline 'Figueira' & 49,30abB & $11,73 \mathrm{bB}$ & 1,42abB & $260,29 b B$ & $37,10 \mathrm{~dB}$ \\
\hline 'Guatambu' & $52,07 \mathrm{aB}$ & $11,88 \mathrm{bB}$ & $1,33 \mathrm{bB}$ & $240,69 b B$ & $55,64 \mathrm{aB}$ \\
\hline 'Tarumã' & $44,57 \mathrm{bB}$ & $22,41 \mathrm{aB}$ & 1,53aB & $491,18 \mathrm{aB}$ & $50,73 \mathrm{bB}$ \\
\hline 'Umbu' & 47,43abB & 7,17bB & $1,57 \mathrm{aB}$ & 170,52bB & $45,82 \mathrm{cB}$ \\
\hline
\end{tabular}

*As médias não ligadas pela mesma letra minúscula (na vertical - diferença entre os cultivares) e maiúscula (na vertical - diferença entre os manejos, com e sem corte, para cada variável) diferem a 5\% de probabilidade de erro pelo teste de Duncan

cultivares 'BRS Guatambu’ e 'BRS Tarumã' são consideradas tardia-precoces, apresentando fase vegetativa longa e reprodutiva curta, resultando em ciclo mais longo. Em contrapartida, as cultivares 'Figueira' e 'Umbu' possuem o ciclo mais curto e com isso menor estatura, sendo menos susceptíveis ao acamamento, além de uma maior capacidade de emissão de afilhos (WENDT et al., 2006). No presente estudo, verificou-se que sem corte as cultivares que possuíram a menor estatura foram a 'Figueira' e 'Tarumã' e no manejo com corte todas as cultivares diferenciaram-se entre si, e a ordem crescente de estatura foi 'Figueira', 'Umbu', 'Tarumã' e 'Guatambu'.

Apesar de todos eles serem considerados materiais de dupla aptidão, as variáveis de componentes de rendimento e a própria produtividade de grãos foram drasticamente reduzidas em todas as cultivares, indicando que sua recomendação como cereal de dupla aptidão deve ser revisada, ou as alturas do corte e o estabelecimento do momento do corte devem ser mais estudados.

A produção de fitomassa seca (Figura 1A) apresentou interação entre as cultivares e as densidades de semeadura. Verifica-se que a cultivar 'BRS Figueira' apresenta um comportamento quadrático, porém o ponto de máxima eficiência técnica não pôde ser estimado pelo fato de este ficar acima do limite de 650 sementes por metro quadrado. As demais cultivares ('Umbu', 'Guatambu' e 'Tarumã') apresentaram respostas lineares à densidade de semeadura. HASTENPFLUG (2009), estudando as mesmas cultivares com diferentes doses de nitrogênio, obteve maior produção de forragem com a cultivar 'BRS Figueira' seguida pelas cultivares 'BRS Umbu', 'BRS Guatambu' e 'BRS Tarumã'. O autor concluiu que a 'BRS Figueira' obteve maior produção de forragem pelo fato de possuir menor relação de folha/colmo, e os colmos mais densos aumentam a fitomassa. A cultivar 'BRS Tarumã' apresenta hábito de crescimento prostrado e isso contribui para que essa cultivar apresente menor produção de fitomassa seca, especialmente quando a produção de forragem é obtida sem pastejo. Em contrapartida, a cultivar 'BRS Figueira' é uma cultivar de porte mais elevado, com maiores participações de colmo na forragem (DEL DUCA et al., 2003). Na comparação das cultivares, com baixa densidade de semeadura (abaixo de 100 sementes $\mathrm{m}^{2}$ ), as que apresentam maiores produções de forragem são as cultivares 'Umbu' e 'Guatambu'. Porém, acima de 150 sementes $\mathrm{m}^{2}$, houve uma inversão na produtividade de massa seca, em que a 'Figueira' apresentou produtividade superior às demais. Os resultados obtidos no presente trabalho indicaram uma produtividade de fitomassa seca de $3.500 \mathrm{~kg} \mathrm{ha}^{-1}$, em uma densidade de 650 sementes $\mathrm{m}^{-2}$. DEL DUCA et al. (2003), utilizando trigo 'BRS Figueira', em baixas densidades, obtiveram uma produção de $1.651 \mathrm{~kg} \mathrm{ha}^{-1}$ de matéria seca, e o rendimento de grãos com um corte foi de $3.062 \mathrm{~kg} \mathrm{ha}^{-1}$, sendo superior ao presente estudo. A diferença entre produtividades de fitomassa seca e produção de grão ocorreu em razão das densidades de semeadura utilizadas (baixa e alta) e dos locais de obtenção dos dados (Rio Grande do Sul e Paraná). 
O comportamento quadrático indica que densidades maiores de semeadura podem ser usadas para aumentar o provimento de forragem no início do inverno, ajudando a amenizar o efeito da deficiência alimentar de outono. Quanto à evolução do número de perfilhos na parcela, verifica-se que houve interação entre as cultivares e as densidades de semeadura (Figura 1B), porém a interação tripla (cultivares $x$ densidades $\mathrm{x}$ manejo de corte) não foi significativa. Dessa forma, o número de afilhos por planta foi superior quando se utilizou o manejo sem corte $(3,29)$, em comparação ao manejo com corte $(2,69)$. Isso pode indicar que as plantas sofreram estresse, o que ocasionou o abortamento dos afilhos, ou então pode indicar que o ponto de crescimento estava acima da região do corte, em razão dos diferentes estádios de crescimento das plantas. A partir desse ponto (150 sementes $\mathrm{m}^{-2}$ ), a ordem das cultivares manteve-se constante, conforme a sua produção de fitomassa seca ('Figueira'> 'Umbu'> 'Guatambu'> ‘Tarumã'). Segundo WENDT et al. (2006), a capacidade da planta para produzir afilhos após o corte é uma característica que influencia a diferença de produção dos cereais. Como apresentado na figura $1 \mathrm{~B}$, a densidade de semeadura influencia a produção de afilhos. VALÉRIO et al. (2008) ressaltam que é preciso adequar a densidade de semeadura para potencializar o afilhamento das cultivares e que a máxima produção de afilhos não está relacionada a altas densidades de semeadura, pois quanto maior a densidade, maior será a competição por luz e nutrientes.

As correlações positivas e significativas que ocorrem em ambos os manejos são a produção de grãos e a massa de espigas $(r>0,93)$. Isso ocorre, provavelmente, pela mobilização dos fotoassimilados em decorrência dos cortes. A massa de cem grãos também se correlacionou $\left(r^{2}>0,80\right)$ com a massa de grãos em cinco espigas (sem corte). Esses resultados concordam com GONDIM et al. (2008), que indicam que a massa de mil grãos e o número de grãos por espiga foram os principais componentes de rendimento. Além disso, a massa de cinco espigas correlacionouse significativamente $\left(r^{2}>0,89\right)$ com a massa de grãos em cinco espigas (positiva e alta), o que não foi verificado para o número de espiguetas em cinco espigas que se correlacionou com o número de grãos em cinco espigas (para ambos os casos, $\mathrm{r}^{2}<0,52$ ). A massa de cinco espigas (sem corte) correlacionou-se com o número de espiguetas em cinco espigas $\left(r^{2}=0,83\right)$ e com a massa de cem grãos $\left(r^{2}=0,64\right)$. Outra correlação importante que ocorreu é a correlação entre a estatura de plantas e a fitomassa seca de plantas $\left(r^{2}>0,99\right)$. Resultados semelhantes foram observados por
CAMARGO \& OLIVEIRA (1983), que observaram correlações fenotípicas positivas e altamente significativas entre produção de grãos e altura das plantas, e entre produção de grãos e número de grãos por espigueta na cultura do trigo, reforçando os resultados do presente estudo. A desfolha e o manejo de irrigação são considerados estresses. Nesse sentido, DENCIC et al. (2000) verificaram que houve alterações na relação causa e efeito entre as variáveis e a produção de grão, indicando assim que pode haver interferência da forma do estresse causado nas plantas.

Dessa forma, em trabalhos de melhoramento ou de experimentação vegetal envolvendo a cultura do trigo duplo propósito, nem sempre é necessário realizar a coleta de todas as variáveis, pois muitas possuem correlação entre si e, além de serem valores altos, essa correlação é obtida na maioria dos casos nos dois manejos. Dessa forma, a indicação de cultivares de trigo para a integração lavoura-pecuária deve levar em consideração a densidade de semeadura, o manejo de corte e o objetivo principal da produção.

\section{CONCLUSÃO}

O corte diminuiu todos os componentes de rendimento, bem como a produção de grãos para todas as cultivares.

\section{AGRADECIMENTOS}

Ao Conselho Nacional de Desenvolvimento Científico e Tecnológico (CNPq) e à Fundação Araucária, pelas bolsas concedidas.

\section{REFERÊNCIAS}

BALBINOT JUNIOR, A.A. et al. Integração lavoura-pecuária: intensificação de uso de áreas agrícolas. Ciência Rural, v.39, n.6, p.1925-1933, 2009. Disponível em: <http://www.scielo.br/ scielo.php? script=sci_arttext \& pid=S0103$847820000900050000107 \%$ l n g = p t \& n r $\mathrm{m}=\mathrm{iso}>$. Acesso em: 19 ago. 2009. doi: 10.1590/S010384782009005000107 .

BORTOLINI, P.C. et al. Cereais de inverno submetidos ao corte no sistema duplo propósito. Revista Brasileira de Zootecnia, v.33, n.1, p.45-50, 2004. Disponível em: <http:/ /www.scielo.br/pdf/rbz/v33n1/a07v33n1.pdf >. Acesso em: 22 mar. 2010. doi: 10.1590/S1516-35982004000100007.

BHERING, S. B. et al. Mapa de solos do Estado do Paraná: legenda atualizada. Rio de Janeiro: EMBRAPA/IAPAR. 2008. 74p.

DAVIDSON, D.J.; CHEVALIER, P.M. Preanthesis tiller mortality in spring wheat. Crop Science, v.30, p.832-836, 1990.

Ciência Rural, v.40, n.8, ago, 2010. 
CAMARGO, C.E.O.; OLIVEIRA, O.F. Melhoramento do trigo: V. Estimativas da herdabilidade e correlações entre altura, produção de grãos e outros caracteres agronômicos em trigo. Bragantia, n.42, p.131-148, 1983.

DEL DUCA, L.J.A. et al. Trigo BRS Figueira: características e desempenhos agronômicos. Passo Fundo: Embrapa Trigo, 2003. 18p. (Embrapa Trigo. Boletim de Pesquisa e Desenvolvimento Online, 18). Disponível em: http:// www.cnpt.embrapa.br/biblio/bp/p_bp18.htm. Acesso em: 12 jun. 2009.

DEL DUCA, L.J.A. et al. Experimentação de genótipos de trigo para duplo propósito na Paraná, em 1999. Passo Fundo: Embrapa Trigo, 2000. 18p. (Boletim de Pesquisa e Desenvolvimento 6)

DENCIC, S. et al. Evaluation of grain yield and its components in wheat cultivars and landraces under near optimal and drought conditions. Euphytica, v.113, p.43-52, 2000. Disponível em: <http://www.springerlink.com/content/t351701417877028/ fulltext.pdf>. Acesso em: 5 mar. 2010. doi: 10.1023/ A: 1003997700865 .

EMPRESA BRASILEIRA DE PESQUISA AGROPECUÁRIA EMBRAPA. Ambiente de software NTIA, versão 4.2.2: manual do usuário - ferramental estatístico. Campinas: Centro Nacional de Pesquisa Tecnológica em Informática para a Agricultura, 1997. 258p.

GONDIM, T.C.O. et al. Análise de trilha para componentes do rendimento e caracteres agronômicos de trigo sob desfolha. Pesquisa Agropecuária Brasileira, v.43, p.487-493, 2008. Disponível em: <http://www.scielo.br/pdf/pab/v43n4/a07v43n4.pdf>. Acesso em: 5 mar. 2010. doi: 10.1590/S0100-204X2008000400007.

HASTENPFLUG, M. Desempenho de cultivares de trigo duplo propósito sob doses de adubação nitrogenada e regimes de corte. 2009. 68f. Dissertação (Mestrado em Produção Vegetal) - Programa de pós-graduação em Agronomia, Universidade Tecnológica Federal do Paraná, Pato Branco, PR.

HÖFS, A. et al. Efeito da qualidade fisiológica das sementes e da densidade de semeadura sobre o rendimento de grãos e qualidade industrial em arroz. Revista Brasileira de Sementes, v.26, n.2, p.54-62, 2004. Disponível em: <http://www.scielo.br/pdf/ rbs/v26n2/24489.pdf>. Acesso em: 19 ago. 2009. doi: 10.1590/ S0101-31222004000200008.
LANGER, R.H.M. Tillering in herbage grass. A review. Herbage Abstracts, v.33, p.141-148, 1963.

MAACK, R. Geografia física do Estado do Paraná. Curitiba: Banco do Desenvolvimento do Paraná, 1968. 350p.

REUNIÃO DA COMISSÃO SUL-BRASILEIRA DE PESQUISA DE TRIGO, Passo Fundo. Indicações técnicas da Comissão Sul-Brasileira de Pesquisa de Trigo. Passo Fundo: Embrapa Trigo, 2006. 164p.

RIEFFEL NETO, S.R. et al. Resposta de arroz irrigado ao arranjo de plantas. Pesquisa Agropecuária Brasileira, v.35, n.12, p. 2383-2390, 2000. Disponível em: <http:// www.scielo.br/pdf/pab/v35n12/a08v3512.pdf>. Acesso em: 19 ago. 2009. doi: 10.1590/S0100-204X2000001200008.

SPARKES, D.L. et al. Does light quality initiate tiller death in wheat? European Journal of Agronomy, v.24, p.212217, 2006. Disponível em: <http://www.sciencedirect.com/ science?_ob=MImg\&_imagekey=B6T67-4HNSBD9-1D\&_cdi=5023\&_user=684709\&_orig = search

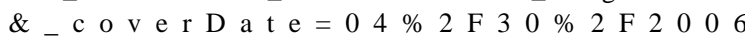
\&_s k = $999759996 \&$ vi e w $=$ c \& w chp $=$ d G L b V t b zSkWb\&md5=da61a176f4bfb5d602220f8a927323d6\&ie=/ sdarticle.pdf $>$. Acesso em: 19 ago. 2009. doi:10.1016/ j.eja.2005.08.003.

VALÉRIO, I. P et al. Desenvolvimento de afilhos e componentes do rendimento em genótipos de trigo sob diferentes densidades de semeadura. Pesquisa Agropecuária Brasileira, v.43, n.3, p.319-326, 2008. Disponível em: <http:/ /www.scielo.br/pdf/pab/v43n3/a05v43n3.pdf>. Acesso em: 19 ago. 2009. doi: 10.1590/S0100-204X2008000300005.

WENDT, W. et al. Manejo na cultura do trigo com finalidade de duplo propósito-forragem e grãos. Pelotas, RS: Embrapa, 2006. (Comunicado técnico. n.141).

ZAFFARONI, E. et al. Análise de caminho nos componentes do rendimento de genótipos de arroz no Rio Grande do Sul. Pesquisa Agropecuária Brasileira, v.33, n.1, p.43-48, 1998. Disponível em: <http://webnotes.sct.embrapa.br/pab/pab.nsf/ 4b 9327 fca 7 faccde 032564 c e 004 f 7 a 6 a / 9 fd 44 f 449 e 23c16d032565a000741478/\$FILE/Pab04196.doc >. Acesso em: 19 ago. 2009. 